\title{
A STUDY OF VARIABLES CHARACTERIZING DRAINAGE PATTERNS IN RIVER NETWORKS
}

\author{
Ling Zhang *, Eric Guilbert \\ Dept. of Land Surveying and Geo-Informatics, the Hong Kong Polytechnic University, \\ Hung Hom, Kowloon, Hong Kong
}

KEY WORDS: River Network, Drainage Pattern, Terrain Analysis, GIS

\begin{abstract}
:
In GIS and in terrain analysis, drainage systems are important components. Due to local topography and subsurface geology, a drainage system achieves a particular drainage pattern based on the form and texture of its network of stream channels and tributaries. Drainage pattern recognition helps to provide a qualitative description of the terrain for analysis and classification and is useful for terrain modelling and visualization and applications in environment. Much research has been done on the description of drainage patterns in geography and hydrology. However automatic drainage pattern recognition in river networks is not well developed. This paper introduces a method based on geometric quantitative indicators to recognize drainage patterns in a river network automatically. Experiment results are presented and discussed.
\end{abstract}

\section{INTRODUCTION}

Drainage system is the pattern formed by streams, rivers and lakes in a drainage basin. As an indivisible part of the land, drainage system is an important component in GIS and in terrain analysis. In a drainage system, streams or rivers always connect together to form networks. In current GIS systems, river networks are stored as line segments with their geographical coordinates and topological relationships. Inside a network, different patterns can be observed and related to other geographical factors. In a drainage basin, a number of factors such as topography, soil type, bedrock type, climate and vegetation cover influence input, output and transport of sediment and water (Charlton, 2008). These factors also influence the nature of the pattern of water bodies (Twidale, 2004). As a consequence, drainage pattern can reflect geographical characteristics of a river network to a certain extent.

There are several types of drainage pattern. At present, much research has been done on the description of drainage patterns in geography and hydrology (e.g. Howard, 1967; Lambert, 1998; Twidale, 2004; Pidwirny, 2006). However, automatic drainage pattern recognition in river networks is not well developed. In this paper, several geometric indicators for the characterization of drainage patterns are presented and discussed on experiments. In GIS, such classification can be useful for terrain analysis or for generalization. At present, many researchers have started to pay attention to geographic features of river networks during the generalization process (Ai et al., 2007; Buttenfield et al., 2010; Stanislawski, 2009, 2011).

The paper is organized as follows. Section 2 briefly reviews related works in drainage pattern. In section 3 , several geometric indicators are presented to recognize drainage patterns in a river network. In section 4 , the method is tested in an experimental area, and the validity of indicators is discussed. Finally, conclusions and research perspectives are presented.

\section{RELATED WORK}

With the passage of time, a drainage system achieves a particular drainage pattern where its network of stream channels and tributaries is determined by local geologic factors. Drainage patterns are classified on the basis of their form and texture according to slope and structure. Their shape or pattern develops in response to the local topography and subsurface geology.

River segments inside a river network can be organised in five types of drainage pattern (Figure. 1). Dendritic pattern (Figure 1a) is the most common form of river system. In a dendritic river system, tributaries of a main river join together in a shape analogous to the twigs of a tree (Lambert, 1998). Parallel patterns (Ritter, 2003) form where there is a pronounced slope to the surface. Tributary streams tend to stretch out in a parallellike fashion following the slope of the surface (Figure 1b). In a trellis pattern (Figure 1c), the main river flows along a strike valley and smaller tributaries feed into it from the steep slopes on the sides of mountains. These tributaries enter the main river at right angles, causing a trellis-like appearance of the river system. The rectangular pattern (Figure 1d) is found in regions that have undergone faulting. Movements of the surface due to faulting offset the direction of the stream. As a result, the tributary streams make sharp bends and enter the main stream at high angles. Reticulate drainage patterns (Figure 1e) usually occur on floodplains and deltas where rivers often interlace with each other forming a net (Simon and Gerald, 2004).

Some experimental works have been done about morphological dependencies of river channel patterns, such as straight, meandering and braid pattern. Schumm and Kahn (1972) obtained an experimental relationship between slope and sinuosity for a fluvial channel, which can show threshold changes between pattern types. Here, sinuosity is a ratio of channel length to valley length. Results show that braided pattern appears on steep low-sinuosity channels. Schumm (1977)

\footnotetext{
* Corresponding author.

E-mail addresses: lingzhang.sky@ connect.polyu.hk (L. Zhang), 1seguil@polyu.edu.hk (E. Guilbert).
} 
improved his model and pointed out that pattern adjustments, measured as sinuosity variations, are closely related to the type, size, and amount of sediment load. Although these works (e.g. Knighton, 1998; Lewin, 2001) about morphological dependencies apply to river channel pattern rather than river network, some of the indicators referred above can be considered in this paper.

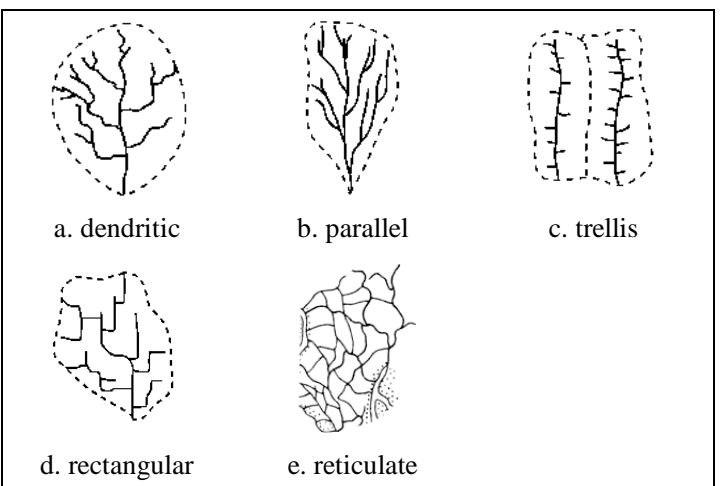

Figure 1. Drainage network patterns (diagrams modified from Ritter, 2006)

At present, much research has been done on the definition, classification and description of drainage patterns in geography and hydrology. Many scholars work on predicting river channel pattern from in-channel characteristic, such as slope and discharge, but not drainage pattern. Indeed, drainage pattern is recognized as an important element in GIS but its classification has not been considered yet. Therefore, the next section studies the geometric and topologic characteristics of each type of river patterns and presents a classification method based on several geometric quantitative indicators in river network.

\section{DRAINAGE PATTERN RECOGNITION}

Based on the description of different drainage patterns, each pattern has its own characteristics, which can be reflected in some quantifiable variable related to some topological and geometrical aspects. Therefore, each pattern can be characterized by a combination of different variables. In this section, the method for drainage pattern recognition is introduced. First, terms describing river networks are defined then classification criteria are introduced and the different steps of the process are detailed.

\subsection{Definition of Features in River Networks}

A river network is composed of several connected river segments. End points of the river segments are the nodes. There are three types of node: the junction node connecting river segments, the source node corresponding to river springs and the outlet towards where the flow goes. A river network is located in a catchment. The catchment controlled by a tributary flowing into a main stream is called a sub-catchment. All these features are illustrated in Figure 2.

The river network forms a tree structure. The structure is built by assigning an order number to each tributary. Ordering starts by assigning order 1 to branchless tributaries. The order of a stream is always higher than the order of its tributaries so that the highest order is assigned to the segment connected to the outlet. Most relevant ordering schemes are the Horton-Strahler scheme based on (Horton, 1945) and modified by Strahler (1957) and the Shreve scheme (Shreve, 1966).

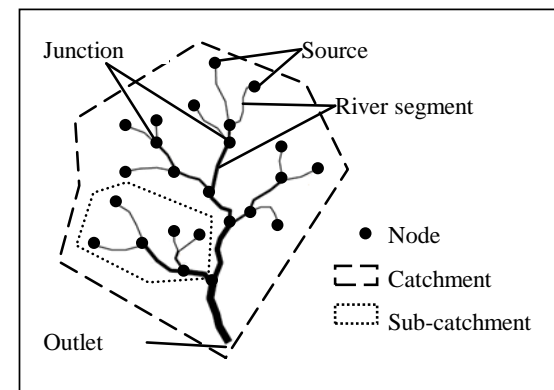

Figure 2. Features in river network (modified from Li, 2007)

\subsection{Drainage Pattern Recognition}

In section 2, 5 types of drainage pattern were introduced. This work addresses the identification of the patterns based on geometric characteristics identified inside a network. According to the description given in section 2, Table 1 proposes a list of characteristics for each of them.

The reticulate pattern is specific as rivers form a cycle instead of a tree. Therefore, recognition of reticulate patterns is discussed in the next section while identification of other patterns based on geometric indicators is introduced in section 3.2.2.

\begin{tabular}{|c|l|}
\hline $\begin{array}{c}\text { Drainage } \\
\text { pattern }\end{array}$ & \multicolumn{1}{|c|}{ Geometric and Topologic Characteristic } \\
\hline Dendritic & $\begin{array}{l}\text {-Tributaries joining at acute angle } \\
\text { - Parallel-like } \\
\text { - Elongated catchment } \\
\text { - Long straight tributaries } \\
\text { Parallel }\end{array}$ \\
Trellis & $\begin{array}{l}\text { - Shibutaries joining at small acute angle } \\
\text { - Tributaries joining at almost right angle } \\
\text { Rectangular }\end{array}$ \\
Reticulate & $\begin{array}{l}\text { - Tributary bends } \\
\text { - Tributaries joining at almost right angle }\end{array}$ \\
\hline
\end{tabular}

Table 1. Drainage pattern characteristic

3.2.1 Reticulate Pattern Recognition: In graph theory, a cut-edge (also known as a bridge) is an edge whose removal produces a graph with more components than the original (Bondy and Murty, 2008). Equivalently, an edge is a bridge if and only if it is not contained in any cycle. The figure 3 illustrates the cut-edges in an undirected graph, where the dashed line is cut-edge and the solid line is edge contained in a cycle.

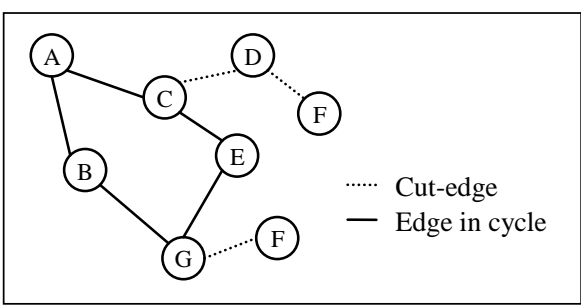

Figure 3. Cut-edges in an undirected graph 
Considering the river network as an undirected graph, all cutedges are found using a bridge-finding algorithm (Tarjan, 1974). Edges which are not identified as cut-edges are components of cycles and form reticulate patterns.

3.2.2 Dendritic, parallel, trellis, and rectangular pattern recognition: In this section, some geometric quantitative indicators are defined to recognize these patterns.

(1)Angle: From the geometric characteristics of drainage patterns in table 1 , the most important variable is the angle formed by a tributary with its main stream at a junction node. The average angle of all angles in a catchment is one quantitative indicator.

(2)Sinuosity: In order to distinguish rectangular pattern, the shape of a tributary is needed. In this pattern, tributary streams make shape bends almost to right angle.

Schumm (1977) set the sinuosity variable of a stream as the ratio of the channel length to the valley length. If the sinuosity ratio is equal to or is greater than 1.5, the channel is considered to be meandering (Ritter, 2003). Only using length value to calculate the sinuosity would lose the information about the river shape. Sometimes a stream seems almost straight, but it would have approximate sinuosity ratio with bending stream, as shown in Figure 4. In order to distinguish angular streams in rectangular pattern from other patterns, a different method is used to identify bended tributaries.

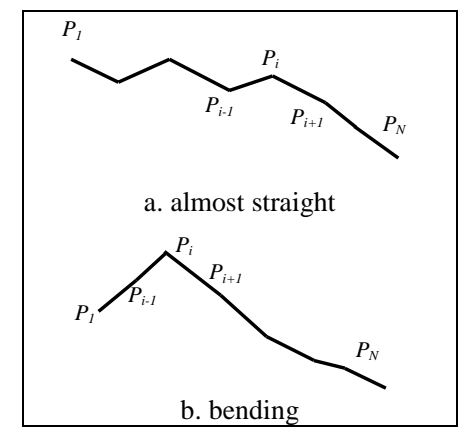

Figure 4 River segment represented as a polyline

Supposing a river segment is composed of $N$ points $P_{i}$ with $P_{l}$ and $P_{N}$ the end points (Figure 4). There are $N-1$ vectors $\overrightarrow{P_{\mathrm{k}} P_{k+1}}(1 \leq k \leq N-1)$. A set of angles $\Omega$ are formed by vectors:

$$
\Omega=\left\{\left(\overrightarrow{P_{1} P_{2}}, \overrightarrow{P_{j} P_{j+1}}\right) \mid 2 \leq j \leq N-1\right\}
$$

If the maximum value among these angles is close to $0^{\circ}$, it indicates that the river segment is almost straight; otherwise, if it is equal to or greater than $90^{\circ}$, it shows that the river segment has an obvious turning which is a bended tributary. So, the maximum value $\operatorname{MAX}(\Omega)$ is used to indicate the river segment sinuosity level.

(3)Length ratio: It is the ratio of tributaries to main stream is the third indicator. The difference between parallel and trellis pattern is length, the tributaries in parallel pattern are long relative to trellis.

Long tributaries in parallel pattern and short tributaries in trellis pattern are relative conception in geography. The river absolute length cannot be used to distinguish different drainage patterns directly. This paper takes the length ratio of tributary to main stream as an indicator. The main stream is not a single river segment connected to the tributary but a series of consecutive segments with the same direction and same order (Figure 5).

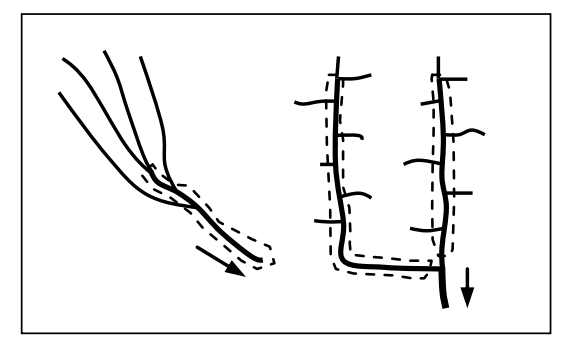

Figure 5 Main streams calculated in length ratio, arrow refers to the flow direction, the river segments in dashed box are main streams.

(4)Catchment elongation: The catchment elongation is characterized by the ratio of the depth to the breadth of the Minimum Bounding Rectangle (MBR) of the catchment. If the catchment is elongated, this ratio is large.

The exact location of the catchment area is usually computed from the DEM which is not available. Approximations can be obtained from the river network such as the convex hull, the axis-aligned bounding box (AABB) or the oriented minimum bounding rectangle (MBR) (Figure 6). The objective is to estimate whether the catchment is elongated or not. The MBR of the river network is considered as it follows the orientation of the network. The breadth of the river network is given by the length of the MBR side which follows the orientation of the main stream while the other side corresponds to the depth. For example, in Figure 6, the depth is smaller than the breadth and the catchment area should be large so the drainage cannot be considered as parallel.

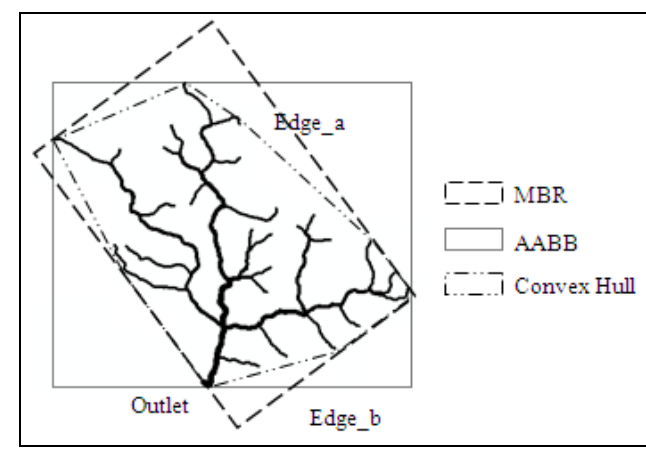

Figure 6 MBR of a river network. The edge Edge_a has a bigger angle with mainstream, ratio = Edge_b / Edge_a $<1$, it is not an elongated river basin.

Geometric characteristics of different patterns presented in Table 1 are only defined qualitatively. In order to identify patterns based on these characteristics, statistical measures are obtained from the network and compared with threshold values.

The first parameter is the angle between the tributaries and the main stream. The parameter is given by the average value $\alpha$ of angles measured at all junctions. Dendritic pattern only requires that junction angles are acute, which can translate by $\alpha<90^{\circ}$. Parallel patterns are characterized by acute angles therefore $\alpha<<90^{\circ}$. For trellis and rectangular patterns, tributaries come at right angle and $\alpha \approx 90^{\circ}$. In the rectangular pattern, most of the tributaries bend to right angle due to faulting zones. So, the 
average value $\beta$ of all river segment sinuosity in a catchment should be equal to or greater than $90^{\circ}$; otherwise, in parallel and trellis, $\beta$ should be smaller than $90^{\circ}$. The parameter average length ratio $\delta$ is used to divide parallel and trellis patterns. In parallel patterns, tributaries have long length so $\delta>1$; otherwise, $\delta<<1$ indicates that most tributaries are shorter than main stream, which occurs in trellis pattern. Parallel and trellis patterns form in elongated catchments and are therefore characterized by high elongation $\gamma$. The different indicators are summarized in Table 3 .

\begin{tabular}{|c|c|c|c|c|}
\hline $\begin{array}{c}\text { Drainage } \\
\text { Pattern }\end{array}$ & $\begin{array}{c}\text { Average } \\
\text { Angle }(\alpha)\end{array}$ & $\begin{array}{c}\text { Average } \\
\text { Sinuosity }(\beta)\end{array}$ & $\begin{array}{c}\text { Average } \\
\text { Length } \\
\text { Ratio }(\delta)\end{array}$ & $\begin{array}{c}\text { Catchment } \\
\text { Elongation }(\gamma)\end{array}$ \\
\hline Dendritic & $\alpha<90^{\circ}$ & - & - & $\gamma<1$ or $\gamma \approx 1$ \\
Parallel & $\alpha<<90^{\circ}$ & $\beta<90^{\circ}$ & $\delta \approx 1$ or $\delta>1$ & $\gamma>>1$ \\
Trellis & $\alpha \approx 90^{\circ}$ & $\beta<90^{\circ}$ & $\delta<<1$ & $\gamma>>1$ \\
Rectangular & $\alpha \approx 90^{\circ}$ & $\beta \approx 90^{\circ}$ & - & - \\
\hline
\end{tabular}

Table 3 List of quantitative indicators

\section{RESULTS AND DISCUSSION}

Experimental evaluation of indicators was done on the Russian river, California at a scale of 1:24,000 (Figure 7) from the Russian River Interactive Information System (RRIIS ${ }^{1}$ ). Algorithms were implemented in $\mathrm{C}++$ using the Boost Graph Library $\left(\mathrm{BGL}^{2}\right)$ to find cycles. The bolder the line, the greater the Horton-Shtrahler. Results are illustrated on several regions shown on Figure 7.

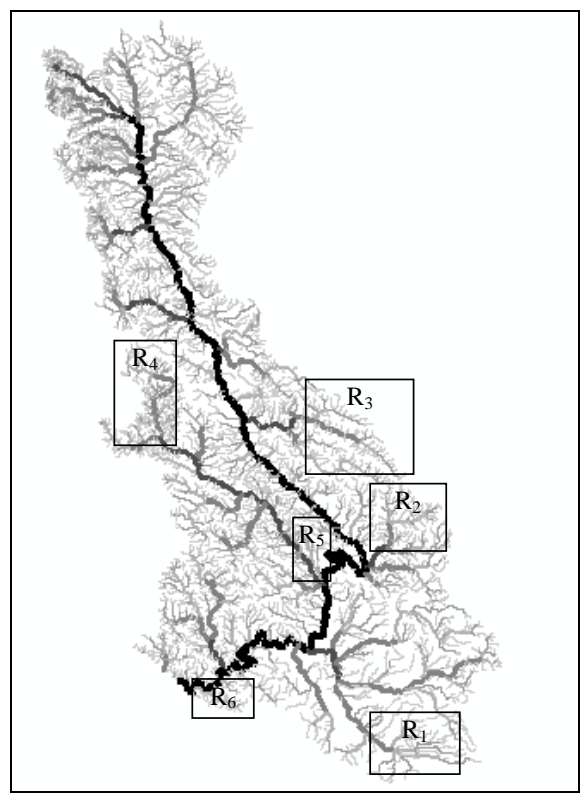

Figure 7. Russian river provided by RRIIS

\subsection{Identification of reticulate networks}

The cut-edge finding algorithm helps us to get the rivers which are not in reticulate part, then, the rest of the river channels are in the reticulate pattern. Figure 8 shows reticulate river networks from region $\mathrm{R}_{1}$ of Figure 7 .

\footnotetext{
${ }^{1}$ http://www.russianriverwatershed.net

${ }^{2}$ http://www.boost.org/doc/libs/1_48_0/libs/graph/doc/index.html
}

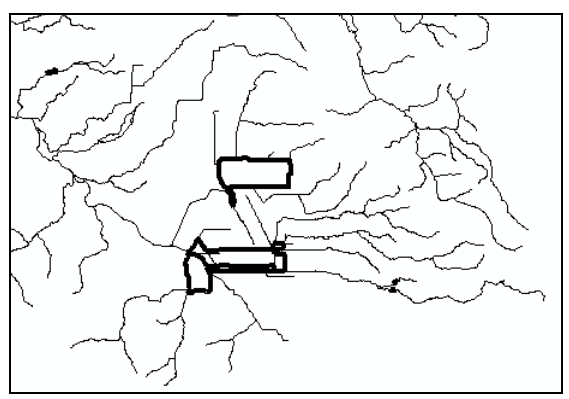

Figure 8. Reticulate pattern in river networks, the solid lines are rivers, and the bold solid lines are reticulate part in the river network.

\subsection{Identification of other networks}

We select several sub-catchments from Russian river basin (Figure 9) and provide the quantifications of average angle, tributary shape and average length ratio and catchment elongation in Table 3. The sub-catchment (a), (b), (c), (d) and (e) are with the biggest Horton-Shtrahler order of 4, 4, 4, 3, and 3 respectively.

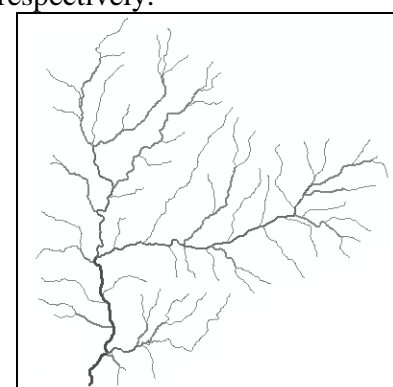

(a)

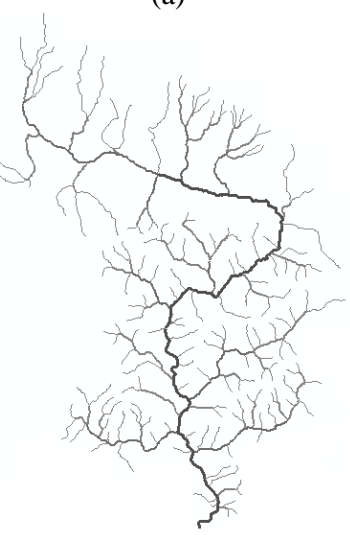

(c)

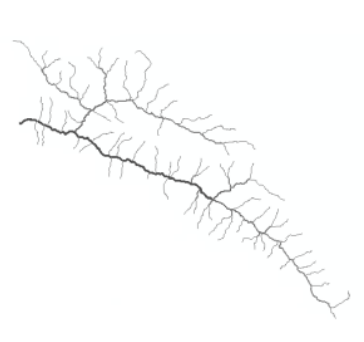

(b)

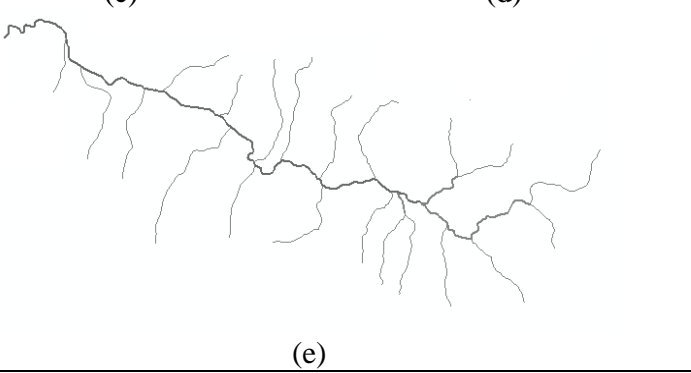

Figure 9. Sub-catchment from Russian river basin, (a), (b), (c), (d) and (e) from regions $\mathrm{R}_{2}, \mathrm{R}_{3}, \mathrm{R}_{4}, \mathrm{R}_{5}, \mathrm{R}_{6}$ respectively. 
From Table 4, the catchment elongations of $S(a)$ and $S(c)$ are quantified as 0.87 and 1.7 respectively, so the $S(a)$ and $S(c)$ are not in elongate catchment and they are not in trellis and parallel pattern. The average sinuosity of $S(a)$ and $S(c)$ are $76.73^{\circ}$ and $59.22^{\circ}$, meaning that the river segments in this two catchments are not bended and most likely do not form a rectangular drainage. In addition, the average angle of $S(a)$ and $S(c)$ are smaller than $90^{\circ}$, so they form a dendritic pattern. As to $S(d)$, it is in an elongated catchment because its elongation value is greater than 2 , and average sinuosity is $59.12^{\circ}$ showing that most stream channels are straight. But, the average angle of $S(d)$ is $49.79^{\circ}$ which is much smaller than $90^{\circ}$, so $S(d)$ is in parallel pattern. The conditions of $S(b)$ and $S(e)$ are similar with $S(d)$ expect the average angle. The average angles of $S(b)$ and $S(e)$ are $81.14^{\circ}$ and $85.43^{\circ}$ respectively that are close to $90^{\circ}$, which explain that most tributaries in $S(b)$ and $S(e)$ join to main streams mostly at right angle. So they are in trellis pattern.

\begin{tabular}{|c|c|c|c|c|c|}
\hline & $\begin{array}{c}\text { Average } \\
\text { Angle }\end{array}$ & $\begin{array}{c}\text { Average } \\
\text { Sinuosity }\end{array}$ & $\begin{array}{c}\text { Average } \\
\text { Length } \\
\text { Ratio }\end{array}$ & $\begin{array}{c}\text { Catchment } \\
\text { Elongation }\end{array}$ & $\begin{array}{c}\text { Drainage } \\
\text { Pattern }\end{array}$ \\
\hline (a) & $51.64^{\circ}$ & $76.73^{\circ}$ & 0.74 & 0.87 & dendritic \\
(b) & $81.14^{\circ}$ & $64.14^{\circ}$ & 0.74 & 3.17 & trellis \\
(c) & $74.66^{\circ}$ & $59.22^{\circ}$ & 0.72 & 1.71 & dendritic \\
(d) & $49.79^{\circ}$ & $59.15^{\circ}$ & 0.59 & 2.24 & parallel \\
(e) & $85.43^{\circ}$ & $72.77^{\circ}$ & 0.62 & 2.87 & trellis \\
\hline
\end{tabular}

Table 4 Information of sub-catchments in figure 9

Quantitative indicators introduced in this paper can characterize the drainage patterns of the river network. However, the indicators may show some limitations in some cases. Length ratios on these examples are within a small range for all types of drainage, meaning that the indicator fails to discriminate the different drainage patterns. Theoretically, the average length ratio of $S(d)$ should be larger than $S(b)$, but the main streams in $S(d)$ are long and the tributaries in $S(b)$ are long. A network, especially at a low order, may also not have enough tributaries to provide a robust classification. For example, in figure 9 (d), only two tributaries connect to a main stream. In such cases, a solution may be to decide of a minimum number of tributaries to form a pattern. No rectangular pattern was identified because the river is not located in a region which underwent faulting.

\subsection{Drainage pattern recognition result}

In the experiment, different catchment units lead to different result. According to Horton-Shtrahler order, we take order 2, 3, and 4 to divide a catchment unit. The smaller the order is, the more the catchment units have. A set of the threshold values is given in table 5 .

\begin{tabular}{|c|c|c|c|}
\hline $\begin{array}{c}\text { Drainage } \\
\text { Pattern }\end{array}$ & $\begin{array}{c}\text { Average } \\
\text { Angle }(\alpha)\end{array}$ & $\begin{array}{c}\text { Average } \\
\text { Sinuosity }(\beta)\end{array}$ & $\begin{array}{c}\text { Catchment } \\
\text { Elongation }(\gamma)\end{array}$ \\
\hline Dendritic & $\left(0,90^{\circ}\right]$ & - & $(0,3)$ \\
Parallel & $\left(0,45^{\circ}\right]$ & $\left(0,90^{\circ}\right)$ & {$[3,+\infty)$} \\
Trellis & {$\left[75^{\circ}, 105^{\circ}\right]$} & $\left(0,90^{\circ}\right)$ & {$[3,+\infty)$} \\
Rectangular & {$\left[75^{\circ}, 105^{\circ}\right]$} & {$\left[90^{\circ}, 180^{\circ}\right]$} & - \\
\hline
\end{tabular}

Table 5 Threshold value of quantitative indicators

Table 6 shows the number of patterns in each order found of each type. 12 reticulate patterns were identified first.

\begin{tabular}{|c|c|c|c|}
\hline & Order 2 & Order 3 & Order 4 \\
\hline Dendritic & 418 & 146 & 36 \\
Parallel & 165 & 8 & 0 \\
Trellis & 13 & 6 & 3 \\
Rectangular & 0 & 0 & 0 \\
Unrecognized & 118 & 7 & 0 \\
Total & 714 & 167 & 39 \\
\hline Reticulate & \multicolumn{3}{|c|}{12} \\
\hline
\end{tabular}

Table 6 Number of drainage patterns

In table 6 , taking order 2 to divide sub-catchments, there are 714 in total number. In this situation, most sub-catchments are made up of only less than 5 tributaries. The samples are too small to get an objective statistic of average value. And there are 118 sub-networks cannot be identified with threshold values of table 5. However, sub-catchment division under order 4 is too large. There are only 39 sub-catchment units. So, although 7 sub-networks have not been identified, the order 3 is a proper base to recognize the drainage patterns in Russian river. Some unclassified networks are shown in figure 10 .

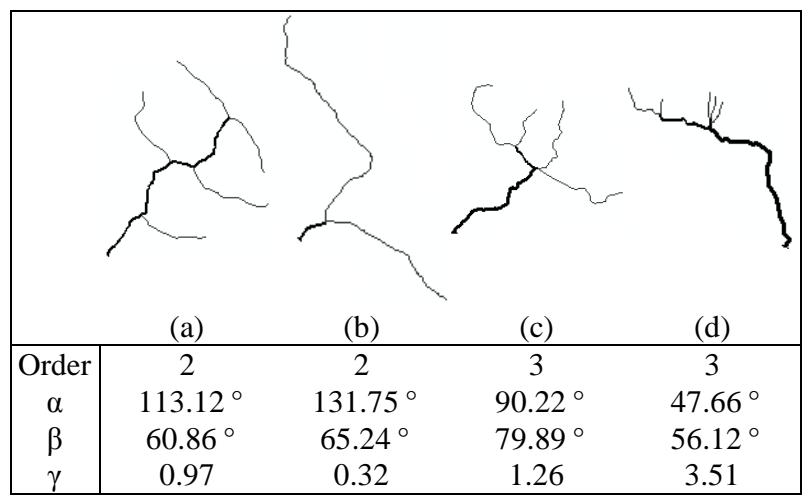

Figure 10. Unclassified sub-networks

In figure 10, the catchments of (a), (b) and (c) are not elongated, and all of them have an average angle bigger than $90^{\circ}$. The catchment of $(d)$ is elongated, however its average angle $\left(47.66^{\circ}\right)$ is not small enough to be a parallel pattern.

\section{CONCLUSIONS}

Drainage pattern is an important geographic factor for river basin. This paper pioneers automatic recognition of drainage patterns in river networks. Five patterns are classified: dendritic, parallel, trellis, rectangular and reticulate patterns. The method is based on geometric indicators, such as the average angle, average sinuosity, and catchment elongation to classify the patterns automatically. The method was applied on a case study, the Russian river basin, and the results were discussed.

The advantage of this work is that proposed geometric quantitative indicators are easy to obtain and calculate. Except the river network data itself, no other information about the terrain is needed. Validation of the results is based on assessments done on case studies. One limitation is that the qualitative description of the patterns relies on quantitative variables and depends on threshold values set by the users.

A first direction for further work may be to introduce fuzzy logic in the classification. Fuzzy logic can provide indication about the likelihood of a network to belong to a pattern. 
Drainage patterns are identified for different sub-networks corresponding to sub-catchments of the main river catchment and can be computed for different orders. The patterns can be organized in a data structure providing a description of the drainage system for each order.

Another aspect is the addition of other parameters for further pattern descriptions. Drainage patterns such as radial and centripetal patterns have not been addressed in this paper. Their characterization needs information relating to spatial relationships between networks rather than geometric indicators. Therefore, on top of parameters related to network geometry, other topologic parameters can be considered.

\section{REFERENCES}

Ai, T., Liu, Y. and Huang, Y., 2007.The Hierarchical Watershed Partitioning and Generalization of River Network. ACTA GEODAETICA et CARTOGRAPHICA SINICA, 36(2), pp. 231-243.

Bondy, J.A. and Murty, U.S.R., 2008.Graph Theory. Springer.

Buttenfield, B.P., Stanislawski, L.V. and Brewer, C.A., 2010. Multiscale representations of water: Tailoring generalization sequences to specific physiographic regimes. GIScience, pp. 1417.

Charlton, R., 2008. Fundamentals of Fluvial Geomorphology. Routledge, N.Y., pp. 1-20.

Horton, R.E., 1945. Erosional Development of Streams and Their Drainage Basins. Geological Society of America Bulletin, 56, pp. 275-370.

Howard, A.D., 1967. Drainage analysis in geologic interpretation: a summation. American Association of Petroleum Geologists Bulletin, 51, pp. 2246-2259.

Knighton, A.D., 1998. Fluvial Forms and Processes: A New Perspective. Oxford Univ. Press, New York.

Lambert, D., 1998. The Field Guide to Geology. Checkmark Books. pp. 130-131.

Lewin, J., Brewer, P.A., 2001. Predicting channel patterns. Geomorphology, 40(3-4), pp. 329-339.

Li, Z.L., 2007. Algorithmic Foundation of Multi-Scale Spatial Representation. Boca Raton, Fla.: CRC Press, pp. 171.

Pidwirny, M., 2006. The Drainage Basin Concept. Fundamentals of Physical Geography, 2nd Edition http://www.physicalgeography.net/fundamentals/10aa.html (22 Dec. 2011)

Ritter, M.E., 2003. The Physical Environment: an Introduction to Physical Geography.

http://www.uwsp.edu/geo/faculty/ritter/geog101/textbook/title_ page.html (22 Dec. 2011)

Schumm, S.A. and Khan, H.R., 1972. Experimental study of channel patterns. Geological Society of America Bulletin, 35, pp. $1755-1770$.

Schumm, S.A., 1977. The Fluvial System. J. Wiley, New York.
Shreve, R.L., 1966. Statistical low of stream numbers. Journal of Geology, 74, pp. 17-37.

Simon, D.F. and Gerald, C.N., 2004. The morphology and formation of floodplain-surface channels, Cooper Creek, Australia. Geomorphology, 60, pp. 107-126.

Stanislawski, L.V., 2009. Feature pruning by upstream drainage area to support automated generalization of the United Stated National Hydrography Dataset. Computers, Environment and Urban Systems, 33(3), pp. 325-333.

Stanislawski, L.V. and Buttenfield, B.P., 2011. Hydrographic Generalization Tailored to Dry Mountainous Regions. Cartography and Geographic Information Science, 38(2), pp. 117-125.

Strahler, A.N., 1957. Quantitative analysis of watershed geomorphology. Transactions of the American Geophysical Union, 8(6), pp. 913-920.

Tarjan, R.E., 1974. A note on finding the bridges of a graph. Information Processing Letters, 2, pp. 160-161.

Twidale, C.R., 2004. River patterns and their meaning. EarthScience Reviews, 67(3-4), pp. 159-218. 